\title{
Island Life: Urban Habitats as Theaters for the Evolution of Biodiversity
}

\author{
Steven N. Handel
}

$I^{s}$ sland archipelagos are more than faraway places with strange sounding names. They lie at the heart of our understanding of ecology and evolution. Since Darwin's stop at the Galapagos Islands of Ecuador, biologists keep turning towards islands for an understanding of biodiversity and the processes that drive adaptation. The famed finches of the Galapagos, the honeycreepers and fruit flies of Hawaii, and the species-rich plant genera on many island sites will draw the curious biologist more than the pink sands, reggae music, and hula dancing that attract less scientific emotions. Darwin's poetic ending to the Origin of Species is a kind of slogan on the foundation of evolutionary studies:

It is interesting to contemplate a tangled bank, clothed with many plants of many kinds, ... endless forms most beautiful and most wonderful have been, and are being evolved.

These oceanic islands led to studies of conceptual islands, pockets of habitat that are surrounded by a contrasting matrix. Managers of reserves and designers of park networks often consider their holdings as islands surrounded by, not seawater, but farm fields, highways, and industrial zones. For this reason, the theory of island biogeography has led to studies of many conceptual islands and how their biological communities form and are sustained. Whether it's a patch of milkweeds surrounded by other wildflowers in an old field or a newly exposed bare surface in the rocky intertidal zone, concepts from the oceanic islands have been tested to see the limits of extrapolation of ecological principles.

Restoration ecologists in their own way are creating islands of habitat surrounded by a contrasting matrix. We struggle with the fundamentals: how many species should we start with; will mutualists arrive; will edge effects weaken birth rates and heighten death rates; will we lose control of the ecological community structure as kids on motorbikes and non-native species sweep through our

Ecological Restoration Vol. 35, No. 3, 2017

ISSN 1522-4740 E-ISSN 1543-4079

(O2017 by the Board of Regents of the University of Wisconsin System. newly planted projects? Some of the core principles of island biogeography are also on our minds, most importantly, immigration rates and extinction rates that reflect distance from species sources and the size of the restored projects we are championing. Landscape ecology reminds us that links and corridors among habitat islands are critical to reach the goals stated at the beginning of a restoration process.

Wandering in our great cities may seem like the antithesis of a holiday on tropical islands. But in the sense that urban habitats are surrounded by a sea of asphalt, concrete, and the barriers of apartment buildings, skyscrapers, and elevated tracks, the smaller urban habitats can be branded as islands floating on the Hardscape Sea.

Just as the Galapagos and Hawaii are icons of evolutionary novelty, work has shown that our urban islands also may be sites of rapid evolutionary change. Selection forces are strong, with urban heat, atypical soils that are chemically and physically different from historic horizons, and disturbances initiated by people all joining to push against the traits of species that have evolved in more rural settings. A suite of studies (see Briggs 2009, Cheptou et al. 2008. Thompson et al. 2016, and others in the Recommended Readings listing) have documented changes in morphological and physiological traits in urban populations of many plant species. Even behavioral traits of urbanized animals are now known to have changed, evolved, under urban island pressures.

Our cities are known as centers of creativity. This usually means theater, art, and choreography. We now know that the creative acts also include modified dispersal and pollination rates, tolerance for soil $\mathrm{pH}$, and leaf morphologies resistant to heat stress. Buy a ticket and get a front row seat, this new evolutionary show will knock your socks off.

As we plan our urban restoration projects the need for attention to these evolutionary changes doesn't make our work easy but will be needed for long-term sustainability, something we all desire. Are the plants and seeds we purchase appropriate for these oddball urban islands, or do they have provenances that will only thrive in out-of-town ecological theaters? Will our urban islands be close enough to other habitat venues to allow for adequate dispersal rates bringing in new seed and young animals as well as dispersal 
and pollination mutualists? Are new urban restoration islands so isolated that they are at the fringes of the native population network and will fade with population extinctions unless long-term and expensive land management is a required project specification? Evolution sometimes occurs quickly, but will change of our initial plant populations occur rapidly enough to match habitat adaptation needs to environmental stresses?

Considering our urban habitats as islands in a sea of constructed problems may focus the protocols of urban work in a different way from restoration work repairing or enlarging most rural habitat preserves. Darwin's "tangled bank" is being replaced around the world with new concrete jungles. Adaptation and evolution as seen in Darwin's voyage of discovery has now landed in our city centers where increasing number of restorationists hone their skills. Evolution isn't ancient history or the stuff of those faraway places, it's downtown. Take the A train and enjoy it.

\section{Recommended Readings}

Briggs, D. 2009. Plant Microevolution and Conservation in HumanInfluenced Ecosystems. Cambridge, UK: Cambridge University Press.

Cheptou, P.O., O. Carrue, S. Rouifed and A. Cantarel. 2008. Rapid evolution of seed dispersal in an urban environment in the weed Crepis sancta. Proceedings of the National Academy of Sciences 105: 3796-3799.

Collinge, S.K. 2009. Ecology of Fragmented Landscapes. Baltimore, MA: Johns Hopkins University Press.

Daou, D. and P. Pérez-Ramos (eds). 2016. New Geographies 8: Island. Cambridge, MA: Harvard University Press.

Darwin, C., 1859. On the Origin of Species by Means of Natural Selection. London, UK: John Murray.

Haila, Y., 2002. A conceptual genealogy of fragmentation research: from island biogeography to landscape ecology. Ecological Applications 12:321-334.

McDonnell, M.J. and A.K. Hahs. 2015. Adaptation and adaptedness of organisms to urban environments. Annual Review of Ecology, Evolution, and Systematics 46:261-280.

Thompson, K.A., M. Renaudin and M.T. Johnson. 2016. Urbanization drives the evolution of parallel clines in plant populations. Proceedings of the Royal Society B 283: 20162180. 